\title{
Aynı Kurumsal Çevredeki Örgütlerin Stratejik Niyetleri Eş biçimli Midir? Vakıf Üniversitelerinin Stratejik Planlarının İçerik Analizi Yöntemiyle İncelenmesi ${ }^{1}$
}

\author{
Kemal DEMIR ${ }^{2}$ ve Üzeyir YILDIZ ${ }^{3}$
}

\section{$\ddot{O} z$}

Örgüt ve yönetim alanında son yıllarda yeni kurumsal kuram giderek artan yoğunlukta çalışılan konular arasında yer almaktadır. Yeni kurumsal kurama göre 'kurumsal çevre' örgütlerin dışında ve üzerinde oluşmuş yapı, kural ve normları içeren bir çevredir. Yeni kurumsal kuram; örgütlerin kurumsal etkiler altında faaliyet gösterdiklerini, örgütlerin yap1 ve süreçlerinin kurumsal çevreye uyum sağlamaları yoluyla eş biçimli hale geldiğini öne sürmektedir. Buna karşın stratejik yönetim yaklaşımı ise; örgütlerin farklılaşarak yaşamlarını sürdürebildiklerini iddia etmektedir. Dolayısıyla bu çalışmanın amacı, aynı kurumsal çevredeki örgütlerin stratejik niyetleri arasında benzerlik ya da farklılaşma olup olmadığını incelemektir. Bu amaçla, vakıf üniversitelerinin stratejik planları içerik analizi yöntemi kullanılarak yeni kurumsal kuram ve stratejik yönetim yaklaşımlarının temel varsayımları üzerinden test edilmiştir. Bu doğrultuda çalışmada öncelikle "stratejik niyet" kavramına ilişkin temalar oluşturulmuş ve bu temalara ilişkin "stratejik niyet" belirten ifadeler ilgili yazın dikkate alınarak tespit edilmiştir. Stratejik niyet ifadelerinin tespiti için stratejik planların misyon, vizyon, amaçlar, hedefler, temel stratejiler, ilke ve değerler başlıkları altında toplanan bölümleri incelenmiştir. Çalışmada elde edilen bulgular vakıf üniversitelerinin stratejik planları arasında farklı düzeylerde eş biçimlilik olduğunu göstermektedir.

Anabtar Kelimeler: Stratejik Yönetim, Kurumsal Kuram, Eş biçimlilik, Farklılaşma

\section{Are The Strategic Intents of Organizations in The Same Institutional Environment Isomorphic? A Qualitative Research on the Strategic Plans of Foundation Universities}

\section{Abstract}

In terms of conceptual background, this study is based on the new institutional theory and strategic management theories, which have been increasingly studied in the field of organization and management in general. According to the new institutional theory, the institutional environment is an environment which includes the structures, rules and norms formed on and outside the organizations. In this context, the basic thesis of the new institutional theory is the assumption that the organizations operate under institutional influences and that the structures and processes of organizations become uniform by their adaptation to the corporate environment. Therefore, the purpose of this study is to examine whether there is a similarity or differentiation between the strategic intentions of the organizations in the same institutional environment. For this purpose, the basic assumptions of new institutional theory and strategic management approaches were tested by examining the strategic plans of foundation universities using content analysis method in March 2012 and in November 2018.Creating of themes on the concept of strategic intent, expressions of strategic intent were identified by the authors. Findings of the study suggest that there are different levels of isomorphism between the strategic plans of foundation universities.

Key Words: Strategic Management, Institutional Theory, Isomorphism, Diversification

\section{Atıf İçin / Please Cite As:}

Demir, K. ve Yıldız, Ü. (2020). Aynı kurumsal çevredeki örgütlerin stratejik niyetleri eş biçimli midir? Vakıf üniversitelerinin stratejik planlarının içerik analizi yöntemiyle incelenmesi. Manas Sosyal Araştırmalar Dergisi, 9(1), 178-189.

\footnotetext{
${ }^{1}$ Bu çalşsma, 11. Ulusal İşletmecilik kongresinde (10-12 Mayıs 2012) sunulan bildirinin genişletilmiş halidir.

2 Dr. Öğr. Üyesi - Yalova Üniversitesi İ̈BF, kemal.demir@yalova.edu.tr - ORCID: 0000-0003-4734-1999

3Arş. Gör. Dr. - Yalova Üniversitesi İIBF, uzeyir.yildiz@yalova.edu.tr - ORCID:0000-0002-8301-9975
} 


\section{Giriş}

Yeni kurumsal kurama göre 'kurumsal çevre' örgütlerin dışında ve üzerinde oluşmuş yapı, kural ve normları içeren bir çevredir. Yeni kurumsal kuram; örgütlerin kurumsal etkiler altında faaliyet gösterdiklerini, örgütlerin yapı ve süreçlerinin kurumsal çevreye uyum sağlamaları yoluyla eş biçimli hale geldiğini öne sürmektedir (Meyer ve Rowan, 1977; Zucker, 1977; Scott ve Meyer, 1983; Dimaggio ve Powell, 1983 Akt: Özen, 2007, s. 240-241). Buna karşın stratejik yönetim; örgütlerin farklılaşarak yaşamlarını sürdürdüklerini iddia etmektedir (Porter, 1980; 1985; 1996; Mintzberg, 1988; Akt: Kale ve Arditi, 2003). Yeni kurumsal kuramın varsayımları ile stratejik yönetim düşüncesinin varsayımlarının birlikte test edilmesi, bu çalışmanın hem sorunsalını hem de özgünlügünü ifade etmektedir.

"Stratejik niyet" (strategic intent) araştırmaları Hamel ve Prahalad (1989; 1994) tarafindan yapılan tanımlayıcı ve öncü çalışmalar ile başlamış ve uluslararası literatürde çok sayıda araştırma ile stratejik niyet çalş̧maları devam etmiştir (örn; Hamilton, Eskin ve Michaels, 1998; Brewer ve Hensher, 1998; Levy, Powell ve Worrall, 2005; Mantere ve Sillince, 2007; Ayoubi ve Massoud, 2007; Srinivashan ve Mishra, 2007; Landrum, 2008; Rui ve Yip, 2008; Darcy ve Pegg, 2011). Ancak, yerli literatürde stratejik niyet konusunda önemli bir boşluk bulunduğu görülmektedir.

Literatürde üzerinde durulan sorunsalların, kurumların stratejik planları üzerinde içerik analizi yapılarak incelenmesi (örn: Demirok, 2011; Toprakçı, İğci ve Yücel,2007) oldukça sık tercih edilen bir yöntemdir. Türkiye'de bugüne kadar üniversitelere ilişkin farklı konuları ele alan çeşitli araştırmalar bulunmaktadır. Bu araştırmalarda YÖK ve üniversitelerin strateji belgelerinin kritik analizi (Ger, 2007), iş hayatına yönelik eğitim alanının şekillenişi (Üsdiken, 2009), yükseköğretim alanının farklılaşması ve benzeşmesi (Üsdiken, Topaler ve Koçak, 2011) ve üniversitelerin rekabetçilik düzeyleri (Kıllınç ve Ağraş, 2010) sorgulanmıştır. Dolayısıyla bu çalışmada da vakıf üniversitelerinin stratejik planlanı incelenerek aynı kurumsal çevredeki örgütlerin stratejik niyetleri arasında farklılaşma mı yoksa eş biçimlilik mi olduğu ortaya konulacaktır.

\section{Kavramsal Çerçeve ve Çalışmanın Sorunsalı}

Kavramsal arkaplan açısından bu çalşma, genelde işletme özelde ise örgüt ve yönetim alanında son yllarda giderek artan yoğunlukta çalışlan yeni kurumsal kuram ve stratejik yönetim teorilerine dayanmaktadır. Yeni kurumsal kurama göre kurumsal çevre örgütlerin dışında ve üzerinde oluşmuş yapı, kural ve normları içeren bir çevredir. Bu bağlamda yeni kurumsal kuramın temel tezi; örgütlerin kurumsal etkiler altında faaliyet gösterdikleri, örgütlerin yap1 ve süreçlerinin kurumsal çevreye uyum sağlamaları yoluyla eş biçimli hale geldiği varsayımıdır (Meyer ve Rowan, 1977; Zucker, 1977; Scott ve Meyer, 1983; DiMaggio ve Powell, 1983 Akt: Özen, 2007, s. 240-241). Yeni kurumsal kuramda aynı örgütsel alanda yer alan örgütlerin taklitçi, ahlaki ve zorlayıcı mekanizmalar nedeniyle daha fazla birbirlerine benzer hale geldikleri savunulmaktadır. Zorlayıcı eş biçimlilik, devlet düzenlemeleri ve politik etkiler nedeniyle ortaya çıkarken, kurumların alanlarında başarılı olan diğer kurumların uygulamalarını taklit etmeleri sonucunda da taklitçi eş biçimlilik ortaya çıkmaktadır. Normatif eş biçimlilik ise, belirli bir alanda profesyonelleşmeden kaynaklı olarak görülmektedir (DiMaggio ve Powell, 1983). Eş biçimlilik olarak ifade edilen bu benzeşme süreci ve mekanizmaları aynı zamanda kuramın da temel inceleme alanını oluşturmaktadır (Çakar ve Danışman, 2012). Dolayısıyla belli bir çevre içinde aynı çevresel koşullarla karşı karşıya kalan örgütleri birbirlerine benzemeye zorlayan süreç olarak ifade edilen ve yeni kurumsal kuramın dayandığ 1 temel kavramlardan biri olan eş biçimlilik kavramı bu çalışmanın ilk odak kavramını oluşturmaktadır.

Yeni kurumsal kuramın kurumsal çevreye yüklediği yoğun anlamın aksine stratejik yönetim; örgütlerin rekabet faktörlerinin etkisi altında, stratejik üstünlükler sayesinde ve yöneticilerinin yetkinliği ile yaşamlarını sürdürdüklerini varsaymaktadır (Porter, 1980; 1985; 1996; Mintzberg, 1988 Akt: Kale ve Arditi, 2003). Yukarıda sözü edilen bu farklılaşma örgüt teorisindeki temel tartışmalardandır (Astley ve Van de Ven, 1983). Dolayısıyla bu çalş̧manın ikinci odak kavramı da stratejik yönetim düşüncesinin öne sürdügü farklılaşma olarak belirginleşmektedir. Bu bağlamda bu çalışma, örneklemde yer alan örgütlerin stratejik niyetlerini eş biçimlilik ve farklılaşma boyutlarında ele almakta ve tartışmaktadır.

Yazında stratejik niyet ile ilgili yapılan çalışmalara bakıldığında kavramla ilgili çeşitli tanımların olduğu görülmektedir. Mantere ve Sillince (2007, s. 409-410) yapmış oldukları çalışmada, yazında farklı yazarlar tarafından yapılan stratejik niyet tanımlarının taşıdığı ortak özellikleri ve hangi araştırmacıların hangi tanımı tercih ettiğini özetlemişlerdir. Yazında stratejik niyet kavramının uzun dönemli ve planlanamayan amaçlar 
(Prahalad ve Doz, 1987, s. 52), kazanmak için paylaşlan tutkular (Hamel ve Prahalad, 1989, s. 64), stratejinin özü, bir duygu, bir rüya, misyon (Hamel ve Prahalad, 1994, s. 129), güçlü öngörü (Burgelman, 1994, s. 25), tepe yönetimin kararları (Burgelman ve Grove, 1996, s. 12), misyon (Hart, 1992, s. 337), tepe yönetimin kurumsal bağlamda işle ilgili genel görüş açısı (Noda ve Bower, 1996, s. 159), amaçların tepe yönetim tarafindan formüle edilişi ve durum ifadesi (Lovas ve Ghoshal, 2000, s. 884) olarak tanımlandığ1 görülmektedir. Yukarıda yer verilen tanımların taşıdığı ortak özelliklere bakılarak stratejik niyet kavramı, "işletmelerin geleceğe doğru ne şekilde ilerlemek arzusunda olduklarını belirten ifadeler" olarak tanımlanabilir. Dolayısıyla bu çalışmada incelenen dokümanlardan elde edilen veriler bu tanım temel alınarak analiz edilecektir.

\section{Yöntem}

$\mathrm{Bu}$ çalışma doküman incelemesiyle elde edilen verilerin içerik analizi yöntemiyle yorumlandığ1 betimsel bir çalışma olarak tasarlanmıştır. Nitel araştırma tekniklerinin sıkça başvurduğu doküman incelemesi yoluyla veri elde etme yöntemi, hatıralar, broşür ve bültenler, raporlar, arşiv belgeleri, süreli yayınlar, planlar vb. her türlü belgeden veri elde etmeyi içermektedir. Bilindiği gibi içerik analizi bir metindeki çok sayıda ünitenin daha az sayıya indirgenerek kategorize edilmesi ile gerçekleştirilmektedir (Altunışık, Coşkun, Bayraktaroğlu ve Yıldırım, 2010, s. 322). İçerik analizinin aşamaları genel olarak analiz ünitesinin tanımlanması, kategorilerin seçilmesi, materyallerin kodlanması, materyallerin tablolaştırılması ve materyallerin sunulması şeklindedir (Altunışı, Coşkun, Bayraktaroğlu ve Yıldırım, 2010, s. 324). Dolayısıyla bu araştırmada elde edilen bulgular, temalar belirlendikten sonra içerik analizi yönemi kullanılarak yorumlanmıştır.

\section{Evren - Örneklem}

$\mathrm{Bu}$ çalışmanın evrenini Türkiye'de kurulan ve faaliyet gösteren rekabetin yoğun olduğu vakıf üniversiteleri oluşturmaktadır. Rekabetin görece düşük olduğu varsayılan devlet üniversiteleri kasti olarak araştırmanın kapsamı dışında bırakılmıştır. Bu doğrultuda çalışmanın evrenini Yüksek Öğretim Kurulu (YÖK) tarafından web sitesinde yayınlanan bilgiye göre Türkiye'de faaliyet gösteren toplam 72 vakıf üniversitesi oluşturmaktadır. Yapılan incelemede ulaşılan 19 üniversitenin stratejik planı örneklemde yer almıştır. Örneklem sayısının artırılması amacıyla, stratejik planına ulaşılamayan 53 üniversitenin eğer varsa strateji geliştirme birimleri sorumlularına, yoksa Genel Sekreterliklerine elektronik posta atılarak stratejik planlarının bulunup bulunmadığı sorulmuştur. Bu yazışmalar sonucunda 1 üniversite stratejik planını araştırmacılarla paylaşırken, 2 üniversite stratejik plan çalışmalarının devam ettiğini belirtmişlerdir. Ayrıca elektronik postaya geri dönüş yapmayan üniversiteler telefonla da aranmıs ve yapılan görüşmelerde üniversitelerin bazıları stratejik plan çalışmaları hazırlıklarının sürdügünü, güncelleme veya yenileme yapıldığını, bazıları da yeni üniversite olduğu için henüz stratejik bir plan hazırlanmadığını ifade etmişlerdir. Dolayısıyla bu çalışmanın veri setini 72 üniversite arasından stratejik plan hazırlayan ve yayınlayan 19 üniversite oluşturmaktadır.

\section{Veri Toplama Araçları}

Üniversitelerin Yayınlamış Olduğu Stratejik Planlar Makalenin veri toplama araçları devlet üniversitelerinin web sayfalarında yayınlanan stratejik planlarıdır. Örneklemde yer alan 19 üniversitenin yayınlanan stratejik planları veri setini oluşturmaktadır.

\section{Verilerin Analizi}

Elde edilen verilerin analizinde öncelikle stratejik planların hemen hepsinde bulunan misyon, vizyon, amaçlar, hedefler, temel stratejiler, ilke ve değerler başlğ̆ altında toplanan bölümler incelenerek stratejik niyet ifadelerinin tespit edilmesi yoluna gidilmiştir. Sözü edilen bölümlerin dışında kalan kısımlar ise, stratejik niyet ifadeleri tanımlamasının aksine, kısa ve orta döneme ilişkin daha somut ifadeleri içermekte olduğu için çalışmanın kapsamı dışında bırakılmıştır.

$\mathrm{Bu}$ doğrultuda araştırmacılar stratejik yönetim düşüncesindeki iç çevre ve dış çevre kavramlarını (Ülgen ve Mirze, 2004) tema olarak belirlemişlerdir. Bu temalardan iç çevre temasi; liderlik, yapı, İKY, finans, eğitim-öğretim, araştırma ve halkla ilişkiler-tanıtım olarak 7 alt temadan oluşmaktadır. Dış çevre teması ise; sektörel, bölgesel, ulusal ve küresel olarak 4 alt temaya ayrılmıştır. Araştırmanın veri setini oluşturan 19 üniversitenin stratejik planları 2 araştırmacı tarafından detaylı bir şekilde ayrı ayrı incelenmiş ve stratejik niyet anlamı içeren ifadeler tespit edilmiştir. Bu incelemeler sonucunda her iki araştırmacı tarafindan ortak olarak stratejik niyet anlamına gelen 44 ifade belirlenmiştir. Elde edilen \% 72 'lik uzlaşma 
oranı güvenirlik için genel kabul gören \% 70'in üstünde olmuş olsa da (Yıldırım ve Şimşek, 2005, s. 233), araştırmacılar tekrar bir araya gelerek belirledikleri ifadeler arasındaki farklılıkları tartışmışlardır. Ayrıca bu aşamada, diğer ifadeler için nitel araştırma teknikleri konusunda deneyimli ve yetkin olan üçüncü bir akademisyenin görüşüne başvurulmuş ve araştırmacılar tarafindan belirlenen ifadeler tekrar değerlendirilmiş ve bu değerlendirmeler sonunda 3 ifade daha ilgili tema başlı̆̆ altına yerleştirilmiştir. Böylece stratejik niyet olarak tanımlanabilecek 47 ifade belirlenmiştir. Bunun sonucunda güvenirlik için uzlaşma oranı tekrar hesaplanmış ve \% 77'lik uzlaşma oranı bulunmuştur. Son aşamada ise temalar altındaki ifadelerin yoğunlaşma düzeyi tartışlarak eş biçimliliğe ilişkin bulgular yorumlanmıştır.

\section{Bulgular}

Araştırmada elde edilen bulgulara göre, stratejik niyetlerin eş biçimlilik gösterip göstermediği sorusunun cevabının, her tema başlığ altında farklı olduğu görülmektedir. Örneğin iç çevre temasının alt boyutlarından olan liderlik ve yönetim boyutunda sadece beş üniversite stratejik niyet ifadesi kullanmışken, diş çevre temasının alt boyutlarından olan uluslararasılaşma-küresel boyutunda iki üniversite dışında tüm üniversiteler stratejik niyet ifadesi kullanmıslardır. Bu ifadelere ilişkin veriler her tema ve alt boyut için ayrı bir tablo olarak gösterilmiş ve yorumlanmıştır.

\section{İç Çevre ve Alt Temalarına İlişkin Bulgular}

Stratejik yönetim düşüncesinde önemli bir yer teşkil eden ve stratejik niyet ifadesine arkaplan oluşturacağ1 düşünülen iç çevre kavramının alt temalarından biri olan liderlik-yönetim ile ilgili 19 üniversitenin 6'sında stratejik niyet ifadesi tespit edilmiştir (Tablo 1). Liderlik-yönetim teması ile ilgili stratejik niyet ifadesine yer veren 6 Üniversite'nin ifadelerine bakıldığında, üniversiteler tarafindan katılımcı, şeffaf, hesap verilebilir, sürdürülebilir yönetim anlayışına vurgu yapıldığı görülmektedir. Araştırmada elde edilen bu bulgu bize üniversitelerin çoğunluğunun liderlik-yönetim alt temasına stratejik planlarında yer vermediğini ve dolayısıyla bu temaya çok fazla stratejik açıdan bakmadıklarını göstermektedir.

Tablo 1. İc Cevre - Liderlik-Yönetim Alt Temast

\begin{tabular}{|c|c|}
\hline$\ddot{U}$ niversite $A d 1$ & Liderlik-Yönetim \\
\hline Bilkent Ü. & $\begin{array}{c}\text { "Bilkent'in çoğunlukla kendi kaynaklarına dayanan, öncü bir üniversite olarak sürdürülebilirliğini } \\
\text { sağlamaktır" }\end{array}$ \\
\hline Çankaya Ü. & $\begin{array}{c}\text { "İnsan hakları bilincinin yükseltilerek ortak bir anlayışın oluşmasına katkı verileceği, uluslararasılaşmanın } \\
\text { sağlanacağı, bilim ve teknolojinin üretilmesi ve kullanılmasında öncü; personeli, ögrencisi ve mezunu } \\
\text { olmaktan gurur duyulan bir Üniversite olmayı sürdürmek." }\end{array}$ \\
\hline İstanbul Aydın Ü. & $\begin{array}{c}\text { "Katılımcı bir yönetim anlayışına sahip olmak" "Strateji ve süreçler ile yönetilen, görev ve yetkiler ile iş } \\
\text { yapma süreçlerinin açık bir şekilde tanımlandığı, kalite süreçleri ile desteklenen katılımc1, şeffaf ve } \\
\text { sürdürülebilir bir yönetim ortamının oluşturulması" }\end{array}$ \\
\hline İstanbul Bilgi Ü. & $\begin{array}{l}\text { "Üniversitenin misyonu, vizyonu, değerleri doğrultusunda sürekli iyileştirme ve mükemmelliği esas alan, } \\
\text { şeffaf, hesap verebilir, çok boyutlu kalite standartları ile desteklenen katıllımc1, demokratik ve insan odaklı } \\
\text { sürdürülebilir stratejik bir yönetişim sistemi ve kültürü oluşturmak" }\end{array}$ \\
\hline $\begin{array}{c}\text { Altınbaş } \\
\text { (Kemerburgaz) Ü. }\end{array}$ & $\begin{array}{l}\text { "Üniversite kaynaklarının mali mevzuata uygun kullanılması yanında etkin, ekonomik ve verimli } \\
\text { değerlendirilmesine yönelik mali yönetim sistemini şeffaf bir yönetim anlayışı içinde güçlendirmek" }\end{array}$ \\
\hline $\begin{array}{l}\text { İstanbul Sabahattin } \\
\text { Zaim Ü. }\end{array}$ & "Şeffaf, hesap verebilir, katılımcı, bürokrasiden arınmış yerinden yönetim" \\
\hline
\end{tabular}

Diğer iç çevre alt temalarından birisi olan Yapı temasında ise, Tablo 2'de görüldüğü gibi 19üniversitenin 7 'sinde stratejik niyet ifadesi tespit edilmiştir. Bu ifadelerde dikkat çeken kavram ise kurumsallaşmadır. Sözü edilen üniversiteler örgüt yapısı ve kurum kültürlerini, yap1 ve işleyişlerini geliştirerek kurumsallaşmak istemektedirler. İç çevrenin Yap1 alt temasında az da olsa üniversiteleri daha rekabetçi ve daha iyi ve kolay bilim, teknoloji ve yenilik üretimi yapabilmeleri için kurumsal ve fiziksel altyapısının geliştirilmesi ve iyileştirilmesine yönelik stratejik niyetlerin belirtildiği görülmektedir. 
Tablo 2. $\dot{I}_{c}$ Cevre - Yapı Alt Teması

\begin{tabular}{|c|c|}
\hline Üniversite Ad1 & Yap1 \\
\hline Iş1k Ü. & "Yapı ve işleyişin geliştirilerek kurumsallaşmanın sağlanması" \\
\hline İzmir Ekonomi Ü. & "Örgüt yapıs1 ve kurum kültürü oluşturarak kurumsallaşma" \\
\hline Bilkent Ü. & $\begin{array}{l}\text { "Geliştirilmiş altyapı, işbirliğine dayalı öğretim, bütünsel bilgi ve önemli problemlerin derslere ve ders } \\
\text { programlarına dahil edilmesiyle birlikte eğitim firsatları daha da kuvvetlendirilecektir." }\end{array}$ \\
\hline Doğuş Ü. & $\begin{array}{c}\text { "Kurumsallaşmayı geliştirmek ve çalışan memnuniyeti artırmak","Iş dünyası ve sanayi ile sağlıklı ve kalıcı } \\
\text { işbirliği geliştirmek için gereken kurumsal altyapıyı oluşturmak" }\end{array}$ \\
\hline $\begin{array}{c}\text { Altınbaş } \\
\text { (Kemerburgaz) Ü. }\end{array}$ & $\begin{array}{c}\text { "Akademik yetkinliği destekleyecek yapılanma, idari personel tanımlanması, fiziki ve teknik altyapı } \\
\text { olanaklarının iyileştirilmesi." }\end{array}$ \\
\hline $\begin{array}{l}\text { İstanbul Medipol } \\
\text { Ü. }\end{array}$ & $\begin{array}{c}\text { "Bilim, teknoloji ve yenilik üretimini kolaylaştırmak için kurumsal altyapıyı geliştirmek" "Üniversiteyi } \\
\text { rekabetçi bir kurumsal ve fiziksel yapıya kavuşturmak" }\end{array}$ \\
\hline $\begin{array}{l}\text { İstanbul Sabahattin } \\
\text { Zaim Ü. }\end{array}$ & $\begin{array}{l}\text { "Akademik ve fiziki alt yapısı ile öne ç1kan...", "Yapılanmada süreçlerle yönetim modelinin uygulanması } \\
\text { ve bütün iş ve yönetim süreçlerinin bilgi teknolojileri altyapısının oluşturulması" }\end{array}$ \\
\hline
\end{tabular}

İç çevre boyutlarından üçüncüsü olan İnsan Kaynakları Yönetimi (IKKY) alt temasına ilişkin olarak ise yine 7 üniversitenin stratejik planında stratejik niyet ifadesi bulgulanmıştır (Tablo 3). İKY alt temasına ilişkin stratejik planlarda tespit edilen stratejik niyet ifadelerinde ise üniversitelerin çoğunun hem ulusal hem de uluslararası kaliteli ögrretim elemanlarının bulunup göreve alınmasına ve öğretim elemanlarının yetkinliğinin arttırlmasina vurgu yaptıkları görülmektedir.

Tablo 3. $\dot{I}_{c}$ Çevre - IKY Alt Teması

\begin{tabular}{|c|c|}
\hline Üniversite $A d i$ & $\dot{I} K Y$ \\
\hline Yeditepe Ü. & "ulusal ve uluslararası derece ve deneyimlere sahip en kaliteli öğretim elemanlarının göreve alınması" \\
\hline Bilkent Ü. & $\begin{array}{c}\text { "dünya standartlarında olan ya da olmak isteyen öğrenci, öğretim elemanı ve çalışanları üniversitemize } \\
\text { katıp onların bizimle kalmasını hedefliyoruz." }\end{array}$ \\
\hline Çankaya Ü. & $\begin{array}{c}\text { "Öğretim elemanlarına gerekli desteği sağlayarak teşvik etmek ve tüm çalışanlara verimli çalışma ortamı } \\
\text { hazırlamak." "İdari personelin motivasyonunu ve görevlerine ait yetkinlikleri artırmak" }\end{array}$ \\
\hline Doğuş Ü. & $\begin{array}{l}\text { "Bilimsel üretimi dünya standartlarına çıkarabilmek için insan kaynakları politikalarında gerekli } \\
\text { değişiklikleri yaparak nitelikli araştırmacı kaynağı oluşturmak ve bu kaynağın devamlılı̆̆ını sağlamak" }\end{array}$ \\
\hline $\begin{array}{c}\text { Altınbaş } \\
\text { (Kemerburgaz) } \ddot{U} .\end{array}$ & $\begin{array}{l}\text { "Akademik personelin eğitim bilimleri açısından donanımının geliştirilmesi”, "Ö̆ğretim Üyesi } \\
\text { kadrolarında nicelik ve yetkinlik olarak artış sağlaması", "Akademik ve araştırma alanında çalışacak idari } \\
\text { insan kaynağına ait yetkinliklerin model ve strateji ile uyumlu olacak şekilde belirlenmesi" }\end{array}$ \\
\hline İstanbul Medipol Ü. & "Öğretim elemanlarının yetkinliğini artırmak" \\
\hline $\begin{array}{l}\text { İstanbul Sabahattin } \\
\text { Zaim Ü. }\end{array}$ & $\begin{array}{c}\text { "Öğretim elemanı temininde, beyin göçünü tersine çevirme noktasında uluslararası kaynaklara yönelme", } \\
\text { "Stratejik insan kaynakları sistemlerini kurma" }\end{array}$ \\
\hline
\end{tabular}

İç çevre altında yer alan bu 3 tema bağlamında örneklemi oluşturan 19 üniversite göz önüne alındığında, stratejik planlarında stratejik niyet ifadesi belirten üniversitelerin sayısının az olduğu ve sadece 3 üniversitenin 3 alt temanın hepsinde stratejik niyet ifadesine yer verdiği görülmektedir. Bu temalarla ilgili stratejik niyet ifadesi belirten üniversitelerin çoğunun ise liderlik-yönetim, yapı ve İKY alt temalarında aynı biçimde davrandığı ve benzer konulara vurgu yaptıkları görülmektedir. Buradan hareketle, bu boyutlarda yüksek yoğunluklu eş biçimlilik görüldüğü, söz konusu eş biçimliliğin ise belirsizliğe karşı standart tepkilerden kaynaklanan öykünmeci eş biçimlilik (DiMaggio ve Powell, 1991, s. 67 Akt: Özen, 2007, s. 265) olduğu değerlendirilmektedir.

İç çevre teması altındaki temalardan birisi olan Araştırma alt temasına ilişkin örneklemdeki üniversitelerin 16's1 stratejik niyet ifadesi belirtmiştir (Tablo 4). Örneklemi oluşturan 19 üniversitenin 16'sının bu alt tema ile ilgili stratejik niyet ifadesi belirtmiş olması, diğer alt temalarla karşılaştırıldığında, üniversitelerin bu alt temaya diğerlerine göre daha fazla önem verdiklerini ve bu temaya daha stratejik baktıklarını göstermektedir. Araştırma kavramının üniversitelerin temel varoluş nedenlerinden ve ana faaliyet konularından birisi olduğu göz önüne alındığında, yukarıda sözü edilen yüksek katılım oranının normal olduğu düşünülmektedir.

Araştırma alt teması ile ilgili stratejik niyet ifadeleri incelendiğinde bilim üretmek, mükemmeliyet, uluslararası ortam ifadelerinin yüksek yoğunlukta bir eş biçimlilik göstergesi olacak düzeyde kullanıldığı gözlemlenmektedir. Türkiye'deki yükseköğretim alanının hızla genişlediği, dünya ile entegresyon sürecinin 
artan bir ivme ile devam ettiği göz önüne alındığında ve özellikle üniversite kurumunun ve bilim üretme faaliyetinin evrenselliği düşünüldüğ̈nde, yüksek yoğunluktaki bu eş biçimliliğin sebebinin meslekleşmeden kaynaklanan normatif eş biçimlilik olduğu düşünülmektedir.

Tablo 4. İc Cevre - Arastırma Alt Teması

\begin{tabular}{|c|c|}
\hline Üniversite Adı & Araştırma \\
\hline Başkent Ü. & "bilimsel üretim yapma ve yaymada ulusal ve uluslararası ortamlarda ön sıralarda yer almak" \\
\hline İstanbul Kültür Ü. & "Ar-Ge Üniversitesi - Bilim Teknoloji Üreten Üniversite" kimliği edinmesini sağlamak" \\
\hline İzmir Ekonomi Ü. & "araştırma odaklı bir üniversite olmak" \\
\hline Sabanc1 Ü. & "yerel avantajları kullanarak uluslararası araştırmada etkin ve önde olunması", \\
\hline Toros Ü. & "akademik mükemmeliyet" \\
\hline Yeditepe Ü. & $\begin{array}{c}\text { "yüksek nitelikli geliştirme ve araştırma programlarıyla öncü bir yükseköğretim ve araştırma kuruluşu } \\
\text { olmaktır", "bilimsel mükemmelliği hedefleyen", }\end{array}$ \\
\hline Attlım Ü. & $\begin{array}{c}\text { "Bilgiyi Üretme ve Kullanmada Performansı Yüksek Alan Yaratmak", } \\
\text { "özgün bilimsel çalışmalarda adı olan” }\end{array}$ \\
\hline Bilkent Ü. & $\begin{array}{c}\text { "Bilkent, hedefe ve ortak çalışmaya odaklı araştırmaların yanı sıra bilimsel merakın tetiklediği bireysel } \\
\text { araştırmacllık içeren buluşlar ve diğer yaratıcı çalışmalarla zenginleşmektedir. Yeni araştırma olanakları } \\
\text { ararken bu faaliyetleri de desteklemeli ve güçlendirmeliyiz." }\end{array}$ \\
\hline Çankaya Ü. & $\begin{array}{c}\text { "Alanındaki gelişmeleri takip ederek, uluslararası düzeyde araştırma-geliştirme çalışmaları yapan, } \\
\text { öğrendiklerini güncel teknoloji laboratuvarlarında uygulayarak bilgi üreten ve bunu toplumsal faydaya } \\
\text { dönüştürebilen bir eğitim sistemi oluşturarak öğrencilere, çalışma hayatına ve topluma katkıda } \\
\text { bulunmak." }\end{array}$ \\
\hline Doğuş Ü. & $\begin{array}{c}\text { "Araştırma ve yayınların nitelik ve niceliğini artırmak" "Çok disiplinli ve disiplinlerarası araştırmalar } \\
\text { yapmak" }\end{array}$ \\
\hline İstanbul Aydın Ü. & $\begin{array}{l}\text { "Araştırmaların sayısal artışının sağlanması", "Araştırmaların niteliğinin yükseltilmesi”, "En az bir } \\
\text { tematik alanda AR-GE faaliyetleri ile farklılaşıp mükemmellik düzeyine ulaşılması" }\end{array}$ \\
\hline İstanbul Bilgi Ü. & $\begin{array}{c}\text { “Öncelikli AR-GE-YE konularında ulusal ve uluslararası düzeyde önde gelen üniversiteler arasında yer } \\
\text { almak" }\end{array}$ \\
\hline $\begin{array}{c}\text { Altınbaş } \\
\text { (Kemerburgaz) Ü. }\end{array}$ & $\begin{array}{c}\text { "İnovasyona yönelik özgür araştırma imkânını ve ortamını sağlamak.", "Ulusal araştırma-geliştirme } \\
\text { stratejileri ve ulusal, bölgesel kalkınma hedefleri ile uyumlu Üniversite araştırma politikasının } \\
\text { belirlenmesi”" }\end{array}$ \\
\hline İstanbul Kültür Ü. & $\begin{array}{c}\text { “Öğretim, bilimsel araştırma ve topluma hizmet konularında ulusal ve uluslararası saygınlığı olan bir } \\
\text { üniversite olmak.” } \\
\begin{array}{c}\text { "Tasarım Fabrikası (DF)'nın geniş kitlelere ulaşarak katma değer yaratan projelere öncü ve destek } \\
\text { olması” }\end{array}\end{array}$ \\
\hline İstanbul Medipol Ü. & $\begin{array}{l}\text { "Üniversitenin bilim, teknoloji ve yenilik üretimini artırmak", "Çağın gereksinimleri ve ulusal öncelikler } \\
\text { çerçevesinde bilimsel faaliyetler ile teknolojik gelişmeleri artırmak, yaygınlaştırmak ve transfer etmek." }\end{array}$ \\
\hline $\begin{array}{c}\text { İstanbul Sabahattin } \\
\text { Zaim Ü. }\end{array}$ & $\begin{array}{c}\text { "üniversitelerimiz arasında ilk yedide yer alan bir araştırma üniversitesi olmak”, "Girişimcilik, } \\
\text { yenilikçilik ve buluşçuluk kültürünü oluşturacak araştırma ve uygulama projelerinin geliştirilmesini } \\
\text { destekleyen altyapılar”, "Ar-Ge faaliyetlerine odaklanma" }\end{array}$ \\
\hline
\end{tabular}

İç çevrenin Eğitim-Öğretim alt temasında ise 15 üniversitenin stratejik planında stratejik niyet ifadesinin olduğu tespit edilmiştir (Tablo 5). Bu ifadelere bakıldığında mükemmellik, farklılık, kalite, uluslararası, dünya standardı gibi vurguların öne çıtığı görülmektedir. Araştırma alt temasına benzer bir şekilde, eğitim-öğretim alt temasında da meslekleşmeden kaynaklanan, fakat orta yoğunlukta, normatif eş biçimlilik gözlemlenmektedir. Araştırma ve eğitim öğretim alt temalarının üniversitelerin temel varoluş nedenlerinden ve ana faaliyet konularından olduğu göz önüne alındığında, üniversitelerin çoğunun stratejik planlarında bu temalara ilişkin ifadelere yer vermesinin normal olduğu düşünülmektedir. 
Tablo 5. $\dot{I}_{c}$ Cevre - Eğitim Ö̈̆retim Alt Teması

\begin{tabular}{|c|c|}
\hline$\ddot{U}$ niversite $A d 1$ & Ĕgitim Öğretim \\
\hline Başkent Ü. & "öğrenmeyi mükemmelleştirmek" \\
\hline Işık Ü. & "Köklü eğitim geleneği ile dünya standardında bir üniversite olmak" \\
\hline İstanbul Kültür Ü. & "Eğitim ve öğretim kalitesinin yükseltilmesi" \\
\hline İzmir Ekonomi Ü. & "eğitimde farklılık yaratmak" \\
\hline Yeditepe Ü. & "eğitimin kalitesini ulusal ve uluslararası mükemmelliğe ulaştırma" \\
\hline Attlım Ü. & $\begin{array}{l}\text { "...ulusal ve evrensel düzeyde donanıma sahip nitelikli bireyler yetiştirmektir. } \\
\text { "nitelikli ve yetkin bireyler yetiştiren" }\end{array}$ \\
\hline Bilkent Ü. & $\begin{array}{l}\text { "Eğitimde Mükemmeliyet" "Dünya Standartlarında Bir Akademik } \\
\text { Topluluk" "Geliştirilmiş altyapı, işbirliğine dayalı ögrretim, bütünsel bilgi ve önemli problemlerin derslere } \\
\text { ve ders programlarına dahil edilmesiyle birlikte eğitim firsatları daha da kuvvetlendirilecektir." }\end{array}$ \\
\hline Çankaya Ü. & “..., yaşam boyu eğitim anlayışına sahip bireyler yetiştirmek.” \\
\hline Doğuş Ü. & $\begin{array}{c}\text { "Eğitim - öğretim, araştırma ve topluma hizmette her zaman mükemmeli hedefleyen bir dünya } \\
\text { Üniversitesi olmaktır." }\end{array}$ \\
\hline İstanbul Aydın Ü. & $\begin{array}{c}\text { "Öğrenci merkezli eğitimi benimsemek", "Yaşam boyu eğitimi desteklemek", "Uluslararası, sistemin } \\
\text { dinamiklerini sorgulayan, araştıran, kendini geliştirmeye odaklı bir eğitim-öğretim anlayışının } \\
\text { pekiştirilmesi” }\end{array}$ \\
\hline İstanbul Bilgi Ü. & $\begin{array}{l}\text { "Eğitim ve Öğretim hizmetlerini mükemmellik düzeyinde sunmak ve bu alanda Türkiye'de ulusal ve } \\
\text { uluslararası öğrenciler tarafindan tercih edilen üniversiteler arasında en üst sıralarda yer almak" }\end{array}$ \\
\hline $\begin{array}{c}\text { Altınbaş } \\
\text { (Kemerburgaz) Ü. }\end{array}$ & $\begin{array}{c}\text { "Dünyanın ve Türkiye’nin ihtiyaçları doğrultusunda kendini güncelleyen, yenilikçi, uygulamayı merkeze } \\
\text { koyan ve öğrenen odaklı bir anlayışa sahip olmak." }\end{array}$ \\
\hline İstanbul Kültür Ü. & $\begin{array}{l}\text { "Eğitim- öğretimi yaratıc1 ve çağdaş temeller üzerinde sürdürürken nitelikli ve başarılı öğrencileri İKÜ’ye } \\
\text { kazandırarak üniversite yaşamında ihtiyaç duyacakları akademik desteği karşlamak." }\end{array}$ \\
\hline İstanbul Medipol Ü. & $\begin{array}{c}\text { "Ĕ̆itimde kalite ve verimliliği artırmak" } \\
\text { "Bilimsel ve mesleki eğitimde kalite, verimlilik ve memnuniyeti artırmak" }\end{array}$ \\
\hline $\begin{array}{l}\text { İstanbul Sabahattin } \\
\text { Zaim Ü. }\end{array}$ & $\begin{array}{c}\text { "Ulusal ve Uluslararası İşbirliklerine Açık, Büyüme ve Gelişme Odaklı, Disiplinler Arası Eğitim-Öğretim } \\
\text { ve Araştırma", "Eğitim ve ögretimde Türkiye ve dünya üniversiteleri ile rekabet edebilecek performansa } \\
\text { dayalı değerlendirme" }\end{array}$ \\
\hline
\end{tabular}

İç çevre temasının son iki alt teması olan "Finans" ve "Tanıtım-Pazarlama" temalarına ilişkin hiçbir üniversitenin stratejik planında stratejik niyet ifadesi tespit edilemediği için bu iki alt temanın tablo olarak görselleştirilmesine gerek duyulmamıştır. Bu alt temalarla ilgili hiçbir vurgunun olmaması bir taraftan eş biçimlilik yorumu yapılabilecek verinin olmadığını akla getirse de, diğer taraftan araştırmacıların bu noktadaki düşüncesi, ilk akla gelen düşüncenin tersine, yüksek yoğun bir eş biçimliliğin sonucu olarak bu boyutların stratejik niyet olarak üniversitelerce vurgulanmaya gerek görülmediği şeklindedir.

\section{Diş Çevre ve Alt Temalarına İlişkin Bulgular}

Dış çevre alt temalarından "Sektörel" temada üniversitelerin stratejik niyet bağlamındaki ifadelere stratejik planlarında çok fazla yer vermedikleri görülmüştür. Sektörel alt teması ile ilgili sadece iki üniversite stratejik planlarında stratejik niyet ifadesine yer vermiştir (Tablo 6).

Tablo 6. Dıș Çevre - Sektörel Alt Teması

\begin{tabular}{cc}
\hline Üniversite $A d \boldsymbol{1}$ & Sektörel \\
\hline Altınbaş (Kemerburgaz) Ü. & "Toplumsal sorunlara ve sektörel ihtiyaçlara yönelik araştırmaların desteklenmesi” \\
İstanbul Kültür Ü. & "öğretim üyelerinin sektör ile olan bağının güçlendirilmesi” \\
\hline
\end{tabular}

"Bölgesel" alt tema ile ilgili olarak da sadece üç üniversite stratejik niyet ifadesinde bulunmuştur (Tablo 7). Bölgesel alt temasıyla ilgili olarak stratejik planlarda yer alan stratejik niyet ifadeleri, üniversiteler tarafindan belli bölgelere katkı yapmak şeklinde vurgulanarak dile getirildiği görülmektedir.

Tablo 7. Dış Cevre - Bölgesel Alt Teması

\begin{tabular}{cc}
\hline Üniversite $A d \boldsymbol{l} 1$ & Bölgesel \\
\hline Başkent Ü. & "Ankara'nın ekonomik gelişmesine, insan gücünün yetiştirilmesine katkı yapmak" \\
İzmir Ekonomi Ü. & "İzmir ve Ege bölgesine katkı sağlamak"
\end{tabular}


DEMIR ve YILDIZ

Aynı Kurumsal Çevredeki Örgütlerin Stratejik Niyetleri Eş biçimli Midir? Vakıf Üniversitelerinin Stratejik Planlarının İçerik Analizi Yöntemiyle İncelenmesi

İstanbul Kültür Ü. “İstanbul’un "bayrak taşıyıcısı” olarak sürdürülebilir multidisipliner araştırma ve girişimcilik ekosistemini beslemek ve ulusal/uluslararası düzeyde toplumsal entegrasyonu sağlamak”

Dış çevrenin bir başka alt teması olan "Sanayi-İş Dünyası" teması ile ilgili olarak ise 9 üniversite tarafından stratejik niyet ifadesi kullanılmıştır (Tablo 8).

Sektörel, bölgesel ve sanayi işbirliği temalarına üniversitelerin stratejik planlarında yer vermemesi, üniversitelerin bu temalara stratejik önem atfetmediklerini düşündürmektedir. Bu temalar ile ilgili stratejik niyet ifadesinde bulunan üniversitelerin ise aynı kavramlara vurgu yaptıkları ve bu bağlamda görece yüksek yoğunluklu bir eş biçimlilik sergiledikleri düşünülmektedir. Dolayısıyla üniversitelerin faaliyet gösterdikleri kurumsal çevrenin biçimleştirici etkileri sonucunda kendi sektörleriyle ilgili bir rekabet analizine ve stratejik niyet ifadesine yer vermedikleri görülmektedir.

Tablo 8. Dış Cevre - Sanayi ve Iss Dünyası Alt Teması

\begin{tabular}{|c|c|}
\hline$\ddot{U}$ niversite $A d 1$ & Sanayi ve $\dot{I}_{S}$ Dünyası \\
\hline İstanbul Kültür Ü. & "Sanayi ilişkilerinde danışlacaküniversite statüsü kazanmak" \\
\hline Okan Ü. & "İş yaşamına en yakın olma" \\
\hline Çankaya Ü. & "Bilimsel çalışmaların ilerlemesine olanak vererek üniversite-sanayi işbirliğini geliştirmek" \\
\hline Doğuş Ü. & "İş dünyası ve sanayi ile işbirliğini geliştirmek" \\
\hline İstanbul Aydın Ü. & “Akademik dünya, iş dünyası ve STK'lar ile ulusal ve uluslararası düzeyde işbirlikleri oluşturmak” \\
\hline $\begin{array}{c}\text { Altınbaş } \\
\text { (Kemerburgaz) } \ddot{U} .\end{array}$ & "Kamu-Sanayi Üniversite iş birliğinin geliştirilmesi”, "Özel sektörle yapılan iş birliklerinin artırılması." \\
\hline İstanbul Kültür Ü. & $\begin{array}{c}\text { “...üniversite sanayi iş birliğinin güçlendirilmesine yönelik projelerin artırllması, öğretim üyelerinin } \\
\text { sektör ile olan bağının güçlendirilmesi...” }\end{array}$ \\
\hline İstanbul Medipol Ü. & $\begin{array}{c}\text { "Bilgi ve teknolojinin, topluma, kamuya ve sanayiye transferini sağlamak", "Üniversite-Sanayi İşbirliği } \\
\text { Ofisi kurulacak ve geliştirilecektir." }\end{array}$ \\
\hline $\begin{array}{l}\text { İstanbul Sabahattin } \\
\text { Zaim Ü. }\end{array}$ & $\begin{array}{c}\text { "Teknoloji Transfer ve Ticarileştirme Merkezi yoluyla sanayi ile ilisskiler", "Sanayi ile ilişskileri yürütecek } \\
\text { sistemler”, "Sürdürülebilir kaynak temini için üniversite-sanayi işbirliği” }\end{array}$ \\
\hline
\end{tabular}

Diș çevre teması altında ele alınan "Ulusal” alt temasına ilișkin olarak toplam 13 üniversitenin stratejik planında stratejik niyet ifadelerine ulaşılmıştır (Tablo 9). Ulusal alt tema ile ilgili stratejik planlarda yer verilen stratejik niyet ifadelerine bakıldığında, üniversitelerin ülkenin gelişimine, toplumsal fayda ve toplumsal duyarlılık konularına vurgu yaptıkları görülmektedir. Araştırmada elde edilen bu bulguya bakılarak, Dış Çevre'nin Ulusal alt temasında politik etkiden ve meşruiyet sorunundan kaynaklanan orta yoğunlukta zorlayıcı eş biçimlilik olduğu değerlendirilmektedir.

Tablo 9. Dış Cevre - Ulusal Alt Teması

\begin{tabular}{|c|c|}
\hline Üniversite $A d ı$ & Ulusal \\
\hline Başkent Ü. & "Ülkemizin ekonomik gelişmesine, insan gücünün yetiştirilmesine katkı yapmak" \\
\hline Okan Ü. & "ülkemizin gelişmesine katkıda bulunmak" \\
\hline Sabanc1 Ü. & $\begin{array}{l}\text { "toplumsal dönüşüme hizmet”, “toplumun çeşitli kesimlerini biraraya getirmek”, “yerel ve uluslararas1 } \\
\text { düzeyde öncü ve örnek bir öğrenim üssü olmak" }\end{array}$ \\
\hline Yeditepe Ü. & " toplumun gelişmesine katkıda bulunmak", \\
\hline Atılım Ü. & "toplumsal duyarlılık ve sürdürülebilirlik anlayışı içinde" \\
\hline Çankaya Ü. & "Toplumsal olaylara duyarlı, sosyal sorumluluk bilinci yüksek ve iş ahlâkına sahip, bireyler yetiştirmek." \\
\hline Doğuş Ü. & $\begin{array}{c}\text { "Ulusal ve Uluslararası işbirliklerini geliştirmek”, "Ülkemizin bilim, teknoloji, sanat ve kültür alanındaki } \\
\text { gelişmelerinde öncü rol üstlenmek ve toplum yararına çalışmalar yürütmektir.", "Topluma sunulan } \\
\text { hizmetleri geliştirmek" }\end{array}$ \\
\hline İstanbul Aydın Ü. & "Ulusal ve uluslararası arenada öğrenciler ve akademisyenler için cazibe merkezi olmak" \\
\hline İstanbul Bilgi Ü. & $\begin{array}{l}\text { "Toplumsal sorunlara duyarlı olmak; çalışanları, öğrencileri ve dış paydaşları ile birlikte toplumun sağlık, } \\
\text { istihdam ve refahının gelişmesine, bilgi, beceri ve yaşam kalitesinin yükseltilmesine katkıda bulunmak" }\end{array}$ \\
\hline $\begin{array}{c}\text { Altınbaş } \\
\text { (Kemerburgaz) Ü. }\end{array}$ & $\begin{array}{c}\text { "Toplumsal sorumluluk bilinciyle özgün katkılar sağlayan çözüm öncelikli üniversite olmak”, } \\
\text { “...topluma katkı sağlayacak uygulamaların tasarlanarak yürütülmesi.” }\end{array}$ \\
\hline İstanbul Kültür Ü. & $\begin{array}{c}\text { "toplumsal fayda yaratmaya yönelik çalışmaların çeşitlendirilmesi”, “toplumsal entegrasyonun } \\
\text { sağlanması" }\end{array}$ \\
\hline
\end{tabular}


İstanbul Medipol Ü. "Çağın gereksinimleri ve ulusal öncelikler çerçevesinde bilimsel faaliyetler ile teknolojik gelişmeleri artırmak, yaygınlaştırmak ve transfer etmek.", "Toplumun mevcut sorun ve ihtiyaçlarına yönelik alanlara öncelik veren bir anlayışla toplumsal gelişime katkı sağlamak."

İstanbul Sabahattin

"Topluma fayda sağlama ve bilgilendirme" Zaim Ü.

Dıș çevre altında son tema olan "Uluslararası-Küresel" teması ile ilgili iki üniversite hariç örneklemde yer alan üniversitelerin tamamının en az 1 stratejik niyet ifadesine yer vermiş olması dikkat çekmektedir (Tablo 10).

Tablo 10. Dış Cevre - Uluslararası-Küresel Alt Teması

\begin{tabular}{|c|c|}
\hline Üniversite $A d ı$ & Uluslararası-Küresel \\
\hline Başkent Ü. & "bilimsel üretim yapma ve yaymada ulusal ve uluslararası ortamlarda ön sıralarda yer almak" \\
\hline Iş1k Ü. & $\begin{array}{c}\text { "Uluslararası tanınırlığa ve saygınlı̆̆a sahip, özgür, özerk, rekabet gücü yüksek, dünyanın } \\
\text { önde gelen üniversiteleri ile işbirliği içinde, disiplinlerarası çalısmalarla yerel değerlerden } \\
\text { evrensel değerlere ulaşmayı amaç edinen, bilim,teknoloji ve sanat alanlarında akla ilk gelen } \\
\text { üniversitelerden biri olmak" }\end{array}$ \\
\hline İstanbul Kültür Ü. & $\begin{array}{c}\text { "Ulusal ve uluslararası düzeyde özgün, bilimsel, teknolojik ve sanatsal nitelikteki projelere } \\
\text { öncülük ederek küresel ve yerel sorunlara çözüm üretmek" }\end{array}$ \\
\hline İzmir Ekonomi Ü. & $\begin{array}{c}\text { "uluslararası işbirliklerini sürdürmek ve artırmak", "küresel bakış açısına sahip mezunlar } \\
\text { yetiştrirmek", "akademik programlarının uluslararası tanınır, geçerli ve itibarlı olmasını } \\
\text { sağlamak ", }\end{array}$ \\
\hline Okan Ü. & $\begin{array}{l}\text { "Toplumun ve iş yaşamının gereksinimlerine evrensel standartlarda yanıt verebilen, yenilikçi } \\
\text { ve öncü bir dünya üniversitesi olmak", "Dünya Üniversitesi Olma", "Uluslararası } \\
\text { Akreditasyon Ölçülerine ve Tanınılırlığına Sahip Bir Üniversite Olmak" }\end{array}$ \\
\hline Sabanc1 Ü. & $\begin{array}{l}\text { "bir dünya üniversitesi olmanın gerektirdiği yapı", "uluslararası stratejik işbirliklerinin } \\
\text { geliştirilmesi", "her stratejik hedefimiz için uluslararası boyutu gözönünde bulundurmak", } \\
\text { "yerel ve uluslararası düzeyde öncü ve örnek bir öğrenim üssü olmak","yerel avantajları } \\
\text { kullanarak uluslararası araştırmada etkin ve önde olunması", }\end{array}$ \\
\hline Toros Ü. & $\begin{array}{c}\text { "geleceğin biçimlenmesine katkıda bulunan uluslararası düzeyde bir kurum olarak tanınmak", } \\
\text { "dünya üniversiteleri, toplulukları ve endüstrisi ile bütünleşmek", "önemli oranda } \\
\text { uluslararasılaştırma" }\end{array}$ \\
\hline Yeditepe Ü. & $\begin{array}{c}\text { "uluslararası düzeyde eğitim hizmeti sağlanması", "Ülkemizin küresel rekabet gücünün } \\
\text { geliştirilmesinde her alanda katkıda bulunacak", "ulusal ve uluslararası standartları aşan } \\
\text { çağdaş bir üniversite kurmak" }\end{array}$ \\
\hline Bilkent Ü. & $\begin{array}{c}\text { "Bilkent bir ‘Dünya Üniversitesi’ olmayı hedeflemektedir.”, “İnsanoğlunun refahına yönelik } \\
\text { faaliyetleri oluşturan, bunlara liderlik eden, katılan ve çözümler üreten, yarının küresel } \\
\text { vatandaşlarını yetiştirmek" }\end{array}$ \\
\hline Çankaya Ü. & $\begin{array}{l}\text { "İnsan hakları bilincinin yükseltilerek ortak bir anlayışı oluşmasına katkı verileceğ́, } \\
\text { uluslararasılaşmanın sağlanacağı, bilim ve teknolojinin üretilmesi ve kullanılmasında öncü; } \\
\text { personeli, ögrencisi ve mezunu olmaktan gurur duyulan bir Üniversite olmayı sürdürmek." }\end{array}$ \\
\hline Doğuş Ü. & $\begin{array}{c}\text { "Ulusal ve uluslararası işbirliklerini geliştirmek", "Üniversitemizin eğitim ve araştırma } \\
\text { faaliyetlerinde uluslararası boyutu güçlendirmek" }\end{array}$ \\
\hline İstanbul Aydın Ü. & "Ulusal ve uluslararası arenada öğrenciler ve akademisyenler için cazibe merkezi olmak" \\
\hline İstanbul Bilgi Ü. & $\begin{array}{c}\text { "Bilimin ve sanatın sınırlarını genişleten, özgürlükçü, toplumsal gelişime önderlik eden, } \\
\text { öğrencileri ile akademik kadrosunun birlikte ögrenme tutkusu etrafında buluştukları, bütün } \\
\text { akademik ve idari bileşenlerinin bu arayışa kendilerini adadıkları uluslararası bir üniversite } \\
\text { olmaktır." }\end{array}$ \\
\hline Altınbaş (Kemerburgaz) Ü. & "Uluslararası yükseköğretim kalite güvence standartlarına uyum sağlanması" \\
\hline İstanbul Kültür Ü. & $\begin{array}{c}\text { "Ulusal ve uluslararası girişimlerin artırılmasına destek sağlanması", "Uluslararasılaşma ile } \\
\text { ilgili her boyut ve birimiyle kurumsal desteğin verilmesi" }\end{array}$ \\
\hline İstanbul Medipol Ü. & $\begin{array}{c}\text { "evrensel bilime katkıda bulunmayı görev kabul etmek", "Uluslararası fikri mülkiyet (patent, } \\
\text { faydalı model, tasarım, vb.) belge sayısı artırlacaktır." }\end{array}$ \\
\hline İstanbul Sabahattin Zaim Ü. & "Uluslararası indekslere kayıtlı dergiler çıkarma" \\
\hline
\end{tabular}

$\mathrm{Bu}$ tema ile ilgili stratejik planlarda yer alan ifadelere bakıldığında, uluslararası-küresel arka planda, oldukça yoğun bir tarzda üniversiteler tarafından uluslararası ortamda tanınma ve dünya üniversitesi olma hedefi gibi vurguların yapıldığı dikkat çekmektedir. Türk yükseköğretim alanının dünya ölçeğindeki etkisinin öncü bir konumda olmadığı gerçeğinden hareketle bu ifadeler belirsizliğe karşı standart tepkilerden kaynaklanan öykünmeci aşırı yoğun eş biçimlilik göstergesi olarak yorumlanmaktadır. 


\section{Tartışma, Sonuç ve Öneriler}

Bu çalışmada vakıf üniversitelerinin stratejik planları içerik analizi yöntemiyle incelenerek stratejik niyet ifadelerinin eş biçimlilik gösterip göstermediği araştırılmıştır. İç çevre teması içerisinde 7 ve dış çevre teması içerisinde 5 alt tema olarak kategorilendirilen stratejik niyet ifadeleri, yeni kurumsal kuramın ve stratejik yönetimin varsayımları altında yorumlanmışır. Çalışmanın sonucunda, iç çevre temaları altında araştırma ve eğitim-öğretim temalarına ilişkin görece yoğun stratejik niyet ifadeleri bulunurken, bunların dışındaki diğer temalarda stratejik niyet ifadelerinin ihmal edilecek düzeyde az olduğu bulgulanmıştır. Dış çevre teması altındaki temalarda da benzer bir durum görülmektedir. Sektörel ve bölgesel temaları ihmal edilecek düzeyde stratejik niyet ifadelerine konu olurken, sanayi-iş dünyası teması orta yoğunlukta, ulusal ve uluslararası-küresel temaları ise aşırı yoğun bir şekilde stratejik niyet ifadelerine konu olmuştur. Örneklemi oluşturan vakıf üniversitelerinin stratejik planlarına yansıyan stratejik niyet ifadelerinin yoğunluğunun, dağılımının ve kullanılan kelimelerin birbirine oldukça benzer bir şekilde yer aldığ tespit edilmiştir. Bu durum araştırmacılar tarafindan vakıf üniversitelerinin stratejik niyetlerinin genel olarak eş biçimlilik gösterdiği şeklinde değerlendirilmiştir.

Bu çalışmada vakıf üniversitelerinin stratejik planları incelenmiş ve yeni kurumsal kuram ve stratejik yönetimin temel varsayımları karşılaştırmalı olarak ele alınarak ilgili yazına bir nebze de olsa katkı sağlanmaya çalışılmışıı. Ayrıca, bu çalışmanın bulgularından yola çıkılarak, gelecekteki çalışmalarda, üniversiteler tarafından yayınlanan konuyla ilgili olabileceği değerlendirilen kalite belgesi, kurumsal değerlendirme raporları ve benzeri belgeler de araştırmaya dâhil edilebilir. Bununla birlikte, yöntem olarak yarı yapılandırılmış görüşmelerle araştırma daha da derinleştirilerek dokümanlardan elde edilemeyen bulgulara erişilmeye çalışlabilir. Ayrıca, farklı ülkelerde faaliyet gösteren yükseköğretim kurumlarının stratejik planları incelenerek karşılaştırmalı çalışmalar da yapılabilir.

\section{Kaynakça}

Altunışık, R., Coşkun, R., Bayraktaroğlu, S. ve Yıldırım, E. (2010). Sosyal bilimlerde araştırma yöntemleri: SPSS uygulamalı. Sakarya: Sakarya Kitabevi.

Astley, W. G. ve Van De Ven, A. H. (1983). Central perspectives and debates in organization theory. Administrative Science Quarterly, 28(2), 245-273.

Ayoubi R.M. ve Massoud H.K. (2007). The strategy of internationalization in universities: A quantitative evaluation of the intent and implementation in UK universities. International Journal Of Educational Management, 21(4), 329349.

Brewer, A. M. ve Hensher, D. A. (1998). Strategic intent and incentives in an industry organisation: The case of the board of airline representatives Australia. Journal of Air Transport Management, 4(2), 87-97.

Burgelman, R. A. (1994). Fadingmemories: A process theory of strategic business exit in dynamic environments. Administrative Science Quarterly, 39, 24-56.

Burgelman, R. A. (1996). A process model of strategic business exit: Implications for an evolutionary perspective on strategy. Strategic Management Journal, 17, 193-214.

Burgelman, R. A. ve Grove, A. S. (1996). Strategic dissonance. California Management Review, 38(2), 8-28.

Çakar, M.ve Danışman, A. (2012). Kurumsal Kuram. Sözen H.C., Basım, H.N. (Der.) Örgüt Kuramları. İstanbul: Beta Yayınevi. 241-271.

Darcy, S. ve Pegg, S. (2011). Towards strategic intent: Perceptions of disability service provision amongst hotel accommodation managers. International Journal of Hospitality Management, 30(2), 468-476.

Demirok, E. (2011). Türkiye'deki kurumların stratejik planlarının incelenmesi. 19.Ulusal Yönetim Ve Organizasyon Kongresi Bildiriler Kitabr, 61-63, 24-26 Mayıs 2011, Çanakkale.

Dimaggio, P.J. ve Powell, W.W. (1983). The iron cage revisited: Institutional isomorphism and collective rationality in organizational fields. American Sociological Review, 48(2), 147-160.

Ger, M. (2007). Yükseköğretim kapsamında stratejik planlamanın evrimi ve YÖK ve üniversitelerin strateji belgelerinin kritik analizi. http://Www.Ydg-Online.Org/Ydg/İndex.Php, 18.01.2012.

Hamel, G. ve Prahalad, C. K. (1989). Strategic intent. Harvard Business Review, May-June, 63-76.

Hamel, G. ve Prahalad, C. K. (1994). Competing for the future. Harvard Business Review, 72(4), 122-128.

Hamilton III, R. D., Eskin, D., \& Michaels, M. P. (1998). Assessing competitors: The gap between strategic intent and core capability. Long Range Planning, 31(3), 406-417.

Hart, S. L. (1992). An integrative framework for strategy-making processes. Academy of Management Review, 17(2), $327-$ 351.

Kale S. ve Arditi D. (2003). Differentiation, conformity, and construction firm performance. Journal Of Management In Engineering, 19(2), 52-59. 
Kılınç, İ. ve Ağraş, S. (2010). Türk üniversiteleri rekabetçi olabilirler mi? Üniversitelerin stratejik planları üzerinden bir değerlendirme. 18.Ulusal Yönetim Ve Organizasyon Kongresi Bildiriler Kitabı, 20-22 Mayıs 2010, Çukurova Üniversitesi İşletme Bölümü, Adana.

Landrum, N. E. (2008). A narrative analysis revealing strategic intent and posture. Qualitative Research in Organizations and Management: An International Journal,3(2), 127-145.

Levy M., Powell P. ve Worrall L. (2005). Strategic intent and E-business in Smes: Enablers and inhibitors. Information Resources Management Journal, 18(4), October-December, 1-20.

Lovas, B. ve Ghoshal, S. (2000). Strategy as guided evolution. Strategic Management Journal, 21(9), 875-896.

Mantere, S. ve Sillince, J.A.A. (2007). Strategic intent as a rhetorical device. Scandinavian Journal Of Management, 23, 406-423.

Meyer, J. W. ve Rowan, B. (1977). Institutionalized organizations: Formal structure as myth and ceremony. American Journal Of Sociology, 83, 340-363.

Mintzberg, H. (1988). Generic strategies: Toward a comprehensive framework. Advances In Strategic Management, P. Shrivista, A. Huff, And J. Dutton, Eds., Jai Press, Greenwich, Conn., 1-67.

Noda, T. ve Bower, J. L. (1996). Strategy making as iterated processes of resource allocation. Strategic Management Journal, 17, 159-193.

Porter, M. E. (1985). Competitive advantage: Creating and sustaining superior performance. Free Press, New York.

Porter, M. E. (1980). Competitive strategy: Techniques for analyzing industries and competitors, Free Press, New York.

Porter, M. E. (1996). What is strategy?. Harvard Business Review, 74(6), 61-78.

Prahalad, C. K. ve Doz, Y. (1987). The Multinational Mission. New York: Free Press.

Ruı H. ve Yip G.S. (2008). Foreign acquisitions by chinese firms: A strategic intent perspective. Journal Of World Business 43, 213-226.

Özen, Ş. (2007). Yeni kurumsal kuram: Örgütleri çözümlemede yeni ufuklar ve yeni sorunlar. AS Sargut ve Ş. Özen (Der) Örgüt Kuramları (237-331). Ankara: İmge.

Scott, W. R. ve Meyer, J. W. (1983). The Organizations of societal sectors. J. W. Meyer Ve W. R. Scott (Der), Organizational Environments: Ritual And Rationality, 129-153, Beverly Hills, Ca: Sage.

Srinivasan, R. ve Mishra, B. P. (2007). Why do firms merge/acquire: An analysis of strategic intent in recent M\&A activity among Indian firms. Immb Management Review, December, 388-402.

Toprakçı, E. G., İğci. S. T. ve Yücel, H. (2007). Türkiye'nin yükseköğretim stratejik planı (YÖK) ile üniversitelerin stratejik planlarının uyumluluğu. 16. Ulusal Eğitim Bilimleri Kongresi Bildiriler Kitabı, Gazi Osman Paşa Üniversitesi Eğitim Fakültesi, Tokat, 5-7 Eylül, 29-37.

Ülgen, H. ve Mirze, S. K. (2004). İsletmelerde stratejik yönetim. İstanbul: Literatür Yayınc1lık.

Üsdiken, B., Topaler, B. ve Koçak, Ö. (2011). Yükseköğretim Alanında Farklılaşma Ve Benzeşme: Türkiye’de Üniversite Modellerinin Tarihsel Seyri, 1900-2010. 19.Ulusal Yönetim Ve Organizasyon Kongresi Bildiriler Kitabı, S.161-163, 24-26 Mayıs 2011, Çanakkale.

Üsdiken, B. (2009). Bir örgütsel alanın yeniden şekillenişi: Türkiye'de iş hayatına yönelik yüksek öğretimde değişim, 1955-1975. METU Studies In Development (Muhan Soysal Special Issue), 35, 1-40.

Yıldırım, A. ve Şimşek, H. (2005). Sosyal bilimlerde nitel araştırma yöntemleri. Ankara: Seçkin Yayıncılık.

Zucker, L. G. (1977). The role of institutionalization in cultural persistance. American Sociological Review, 42, 726-743.

\section{EXTENDED ABSTRACT}

In terms of conceptual background, this study is based on the new institutional theory and strategic management theories, which have been increasingly studied in the field of organization and management in general. According to the new institutional theory, the institutional environment is an environment which includes the structures, rules and norms formed on and outside the organizations. In this context, the basic thesis of the new institutional theory is the assumption that the organizations operate under institutional influences and that the structures and processes of organizations become uniform by their adaptation to the corporate environment (Meyer and Rowan, 1977; Zucker, 1977; Scott and Meyer, 1983; DiMaggio and Powell, 1983 cited in Özen, 2007, 240-241). Therefore, the first focus concept of this study constitutes the concept of isomorphism which constitutes the basic area of investigation of the new institutional theory. Contrary to the intense meaning of the new institutional theory on the institutional environment, strategic management assumes that organizations continue to live under the influence of competitive factors, thanks to strategic advantages and the competence of their managers (Porter, 1980; 1985; 1996; Mintzberg, 1988 cited in Kale and Arditi, 2003). This differentiation mentioned above is one of the main debates in organizational theory (Astley and Van de Ven, 1983). Therefore, the second focus concept of this study is the differentiation suggested by the idea of strategic management. In this context, in this study, strategic intentions of organizations are discussed in terms of isomorphism and differentiation dimensions. The assumptions of the new institutional theory and the assumptions of the strategic management thought together express both the problematic and the specificity of this study. 
Research on strategic intentions began with descriptive and pioneering work by Hamel and Prahalad (1989; 1994) and continued with numerous studies in the international literature (ei; Hamilton, Eskin and Michaels, 1998; Brewer and Hensher, 1998; Levy, Powell and Worrall, 2005; Mantere and Sillince, 2007; Ayoubi and Massoud, 2007; Srinivashan and Mishra, 2007; Landrum, 2008; Rui and Yip, 2008; Darcy and Pegg, 2011). However, there is a significant gap in the area of strategic intent in the national literature. Therefore, in this study, the strategic plans of foundation universities are examined, there was an attempt to contribute to this gap in the related field by showing that there is isomorphism or differentiation among the strategic intentions of the organizations in the same institutional environment.

This study was designed as a descriptive study which was interpreted by the content analysis method. The study population consisted of a total of 72 foundation universities operating in Turkey. Therefore, the data set of this study consisted of 19 universities comprising 72 universities, which prepared and published a strategic plan. The findings obtained in this research were interpreted by using the content analysis method after the themes were determined.

In this context, the internal environment and external environmental concepts in the strategic management theory (Ülgen and Mirze, 2004) were determined as the theme in the research. The themes of the interior environment are; leadership, structure, HRM, finance, education, research and public relations-promotion consists of 7 sub-themes. The external environment themes were divided into four sub-themes as sectoral, regional, national and global. Afterwards, the strategic plans of the 19 universities that formed the data set of the study were examined separately by 2 researchers and the expressions containing the meaning of strategic intent were determined. As a result of these investigations, 44 statements were determined by both researchers as strategic intent. Although the $72 \%$ consensus rate reached over, 70\% generally accepted for reliability (Yıldırım and Şimşek, 2005: 233), the researchers reunited and discussed the differences between the expressions they determined. In addition, at this stage, a third academician, who is experienced and competent in qualitative research techniques for other expressions, was consulted and the statements determined by the researchers were re-evaluated, and at the end of these evaluations, 3 more statements were placed under the related theme. Thus, 47 expressions were defined as strategic intent. As a result, the reconciliation rate for reliability was re-calculated and a reconciliation rate of $77 \%$ was found. In the final stage of the study, the concentration level of the expressions under the themes was discussed and the findings related to the isomorphism were interpreted.

As a result of the study, while there are relatively intense strategic intentions related to research and teaching-teaching themes under the themes of internal environment, it was found that the expressions of strategic intent were less than negligible in other themes. A similar situation was observed in themes under the theme of external environment. While the sectoral and regional themes are subject to the expressions of strategic intentions to be neglected, the industrial-business world theme has been subject to medium intensity, while the national and international-global themes are heavily subject to the statements of strategic intent. It was determined that the intensity, distribution and the words of the strategic intentions reflected in the strategic plans of the foundation universities that make up the sample were quite similar. This situation was evaluated by the researchers as the strategic intentions of foundation universities in general.

In this study, strategic plans of foundation universities were eliminated. In future studies, the quality certificate, institutional evaluation reports and similar documents, which are considered to be related to the subject published by the universities, may be included in the research. However, as a method, semistructured interviews can be done to deepen the research and the findings cannot be obtained from the documents. In addition, comparative studies can be conducted by examining the strategic plans of higher education institutions operating in different countries. 